\title{
Prevalence of Oncogenic Human Papillomavirus Genotypes Among Sexually Active Women in Parakou (Benin, West Africa)
}

\author{
Christianne Gandekon ${ }^{1}$, Rachidi Sidi Imorou ${ }^{1}$, Théodora Zohoncon ${ }^{2,3}$, Moutawakilou Gomina ${ }^{1, ~}$, \\ Alice Ouedraogo ${ }^{3,4}$, Ina Traore ${ }^{4}$, Essolokina Dolou ${ }^{3}$, Prosper Bado ${ }^{3,4}$, Esther Traore ${ }^{3,4}$, \\ Charlemagne Ouedraogo ${ }^{4}$, Jacques Simpore ${ }^{2,3,4}$, Simon Akpona $^{1}$ \\ ${ }^{1}$ Faculty of Medicine, University of Parakou, Parakou, Republic of Benin \\ ${ }^{2}$ Faculty of Health Sciences, University Saint Thomas d'Aquin, Ouagadougou, Burkina Faso \\ ${ }^{3}$ LABIOGENE, CERBA, Ouagadougou, Burkina Faso \\ ${ }^{4}$ UFR Life and Earth Sciences, University Ouaga I Professeur Joseph KI-ZERBO, Ouagadougou, Burkina Faso \\ Email address: \\ elboutraguero@yahoo.fr (M. Gomina) \\ ${ }^{*}$ Corresponding author
}

\section{To cite this article:}

Christianne Gandekon, Rachidi Sidi Imorou, Théodora Zohoncon, Moutawakilou Gomina, Alice Ouedraogo, Ina Traore, Essolokina Dolou, Prosper Bado, Esther Traore, Charlemagne Ouedraogo, Jacques Simpore, Simon Akpona. Prevalence of Oncogenic Human Papillomavirus Genotypes Among Sexually Active Women in Parakou (Benin, West Africa). Journal of Gynecology and Obstetrics.

Vol. 8, No. 4, 2020, pp. 102-107. doi: 10.11648/j.jgo.20200804.16

Received: June 25, 2020; Accepted: July 13, 2020; Published: July 28, 2020

\begin{abstract}
Background: The genital infection due to Human papillomavirus (HPV) is considered as the most common sexually transmitted infection across the world, including high-risk oncogenic HPV (HR/HPV). Objective: This study aimed to determine the prevalence of HR/HPV genotypes among sexually active women in Parakou (Benin) in 2017. Methods: This research work was a cross-sectional descriptive study carried out in the city of Parakou (Benin), from January 15 to April 15, 2017. Sample consisted of 247 sexually active women selected through a systematic random sampling. Cervical specimens collected with swab were subject to multiplex PCR to characterize 14 HR/HPV genotypes. Results: The prevalence of $\mathrm{HR} / \mathrm{HPV}$ infection was rated 32.8\% [95\% CI: 27.1-39.3]. All the fourteen HR/HPV genotypes investigated were detected using PCR among our study population. The most common types of HR/HPV were, in descending order, HPV45 (25.9\%), HPV35 (18.5\%), HPV52 (17.3\%), HPV51 (16.0\%) and HPV58 (14.8\%). HPV16 and 18 were found out at respective proportions of $2.5 \%$ and $7.4 \%$. Age group 20 years or less had the highest prevalence of HR/HPV infection (55.7\%) followed by age group from 21 to 30 years $(38.3 \%)$. Conclusion: The prevalence of HR/HPV infection is high among sexually active women in Parakou in 2017 and the most frequent HR/HPV are not those found commonly in precancerous and cancerous cervical lesions.
\end{abstract}

Keywords: High-Risk HPV, Prevalence, Real Time PCR, Women, Benin

\section{Introduction}

Human papillomavirus (HPV) infection is one of the most widespread sexually transmitted infections across the world; more than half the sexually active women get infected with it during their existence $[1,2]$. Nowadays, more than $200 \mathrm{HPV}$ genotypes were identified and classified into two major groups i.e. low-risk HPV and high-risk HPV (HR/HPV), according to whether they cause benign lesions or lesions likely to evolve towards malignant tumors [3, 4]. Epidemiological studies and experimental data showed that although there is viral clearance in the infection, the 
persistence of $\mathrm{HR} / \mathrm{HPV}$ infection plays a critical role in the development of cancer, and most cervical cancers are associated with $\mathrm{HR} / \mathrm{HPV}$ [5]. In fact, $\mathrm{HR} / \mathrm{HPV}$ may be identified virtually in nearly all cervical cancers [4].

With an estimated 570,000 cases and 311,000 deaths in 2018 worldwide, cervical cancer ranks as the fourth most frequently diagnosed cancer and the fourth leading cause of cancer death in women [6]. The highest regional incidence and mortality rates are seen in Africa, with rates elevated in Southern Africa, Eastern Africa, and Western Africa [6]. In relative terms, the rates are 7 to 10 times lower in North America, Australia/New Zealand, and Western Asia [6]. In recent years, clear evidence supports the use of HPV-based tests for the detection of precursor lesions of the cervix [7]. In a randomized trial in India, HPV testing offered greater protection against invasive cervical cancer than either visual inspection with acetic acid or cytology [8].

The prophylactic nonavaccine licensed in 2014, only available in certain regions, target genotypes 6 and 11 which are the cause of benign genital lesions and the next five most common cancer-causing HPV types (HPV 31/33/45/52/58) after HPV 16/18, thus enabling a primary prevention [9]. The genotypes targeted by those vaccines sometimes are not the most encountered in some African regions. Besides, till now there are no vaccines available for the other high-risk oncogenic genotypes. Studies conducted in the West African sub-region confirm the existence of those high-risk genotypes, particularly in Burkina Faso [10-12], Côte d'Ivoire [13], Senegal and Mali [14], and in Nigeria [15]. In Benin, the research works of Piras et al. [16] and Zohoncon et al. [17] reported HR/HPV genotypes other than HPV16 and 18 .

This study aimed to determine the prevalence of HR/HPV genotypes among sexually active women in Parakou (Benin) in 2017 in order to specify the genotypes circulating in the study area.

\section{Patients and Methods}

\subsection{Study Setting and Respondents}

We conducted a cross-sectional descriptive survey during the period running from January 15 to April 15, 2017. During the said survey, each subject was put questions and only one sample was collected from her. Sample consisted of 247 sexually active women living in the city of Parakou, received for systematic screening, recruited by an exhaustive sampling at the Borgou Regional University Teaching Hospital during the study period. This study included all non-pregnant women and young girls who gave their free and informed consent about the relevance of the study. The study excluded any woman or young girl, virgin or pregnant, or who underwent total hysterectomy. The sociodemographic, behavioral and sexual variables related to lifestyle and gynecological and obstetrical history were collected on the basis of a questionnaire.

\subsection{Sample Collection}

Endocervical samples were collected with sterile swab during gynecological or pelvic exam. Those endocervical samples or specimens were stored in a freezer at $-80^{\circ} \mathrm{C}$ while awaiting DNA extraction, and carried to Ouagadougou at CERBA/LABIOGENE where biomolecular analysis was performed.

\subsection{Extraction of Viral DNA, Detection and Typing of $\mathrm{HR} / \mathrm{HPV}$}

Viral DNA was extracted using DNA-Sorb-A kit (Sacace Biotechnologies, Como, Italy) following the manufacturer's protocol.

The characterization of HR/HPV genotypes was done by real time PCR [11] using HPV Genotypes 14 Real-TM Quant (Sacace Biotechnologies, Como, Italy) which helps detect the following $14 \mathrm{HR} / \mathrm{HPV}$ genotypes: 16, 18, 31, 33, 35, 39, 45, $51,52,56,58,59,66$ and 68. Whole-genome amplification was performed using Sacycler-96 Real time PCR (Sacace Biotechnologies, Como, Italy). It was a multiplex amplification of target area primers (gene L1 and oncoproteins E6 and E7) of HR/HPV, and human beta globin gene as intern control. For each sample, tested PCR-mix-1 were PCR-mix-1 16, 18, 31, IC; PCR-mix-1 39, 45, 59, IC; PCR-mix-1 33, 35, 56, 68 and PCR-mix-1 51, 52, 58, 66. Results were interpreted using Microsoft Excel software "HPV 14 genotypes Real TM.xls" supplied by the manufacturer.

\subsection{Data Processing}

The qualitative variables were presented as percentages and those quantitative as averages and standard deviation. The data were processed using STATA 13 software.

\subsection{Ethical Considerations}

The protocol of this study has been approved by the Ethics Committee for Biomedical Research of the University of Parakou under No. 22-CLERB-UP/P/SP/R/SA dated October 29, 2016. It has also been authorized by the Regional Director of Health for Borgou \& Alibori under No. 1574/16/MS/DDS-BA/SDSP/SA dated December 26, 2016.

\section{Results}

\subsection{Sociodemographic and Sexual Behavioral Features of the Study Population}

Mean age for study population was $33.4 \pm 9.7$ years. The youngest female subject was aged 19 years and the oldest one was 60 years. Group ages from [21 to 30 years] and from [31 to 40 years] were predominant with respective percentages of 43.3 and 30.4. Table 1 shows the sociodemographic and sexual behavioral characteristics of the study population. 
Table 1. Sociodemographic and sexual behavioral characteristics of the study population, Parakou, January/April 2017 ( $n=247)$.

\begin{tabular}{|c|c|c|}
\hline Variables & Population size & Percentage \\
\hline \multicolumn{3}{|l|}{ Age (years) } \\
\hline$\leq 20$ & 9 & 3.6 \\
\hline [21-30] & 107 & 43.3 \\
\hline$[31-40]$ & 75 & 30.4 \\
\hline$[41-50]$ & 44 & 17.8 \\
\hline$[51-60]$ & 12 & 4.9 \\
\hline \multicolumn{3}{|l|}{ Civil status } \\
\hline Single & 82 & 62.7 \\
\hline Married & 155 & 33.2 \\
\hline Divorced & 4 & 1.6 \\
\hline Widowed & 6 & 2.4 \\
\hline \multicolumn{3}{|l|}{ Occupation } \\
\hline Trader & 40 & 16.2 \\
\hline Civil servant & 44 & 17.8 \\
\hline High school/University female student & 47 & 19.0 \\
\hline Craftswoman & 19 & 7.7 \\
\hline Housewives & 97 & 39.2 \\
\hline \multicolumn{3}{|l|}{ Educational status } \\
\hline Illiterate & 87 & 35.3 \\
\hline Primary/secondary & 108 & 43.7 \\
\hline University & 52 & 21.0 \\
\hline \multicolumn{3}{|l|}{ Sociocultural groups } \\
\hline Bariba and allied ethnic groups & 62 & 25.1 \\
\hline Dendi and allied ethnic groups & 23 & 9.3 \\
\hline Aja and allied ethnic groups & 7 & 2.8 \\
\hline Lokpa and allied ethnic groups & 10 & 4.0 \\
\hline Yoruba and allied ethnic groups & 41 & 16.6 \\
\hline Fon and allied ethnic groups & 44 & 17.8 \\
\hline Fulani and allied ethnic groups & 35 & 14.2 \\
\hline Somba and allied ethnic groups & 13 & 5.3 \\
\hline Other country* & 12 & 4.9 \\
\hline \multicolumn{3}{|l|}{ Parity } \\
\hline Nulliparous & 73 & 29.6 \\
\hline Primiparous & 30 & 12.1 \\
\hline Pauciparous & 67 & 27.1 \\
\hline Multiparous & 56 & 22.7 \\
\hline Grand multiparous & 21 & 8.5 \\
\hline \multicolumn{3}{|l|}{ Current number of sexual partners } \\
\hline $0 * *$ & 6 & 2.4 \\
\hline 1 & 236 & 95.5 \\
\hline 2 & 4 & 1.6 \\
\hline 3 & 1 & 0.4 \\
\hline \multicolumn{3}{|l|}{ Use of condom } \\
\hline Never & 143 & 57.9 \\
\hline Not frequently & 30 & 12.1 \\
\hline
\end{tabular}

\begin{tabular}{lll}
\hline Variables & Population size & Percentage \\
\hline Sometimes & 59 & 23.9 \\
$\begin{array}{l}\text { Every time } \\
\text { Age at first sexual intercourse (years) }\end{array}$ & 15 & 6.1 \\
$\leq 10$ & 1 & \\
{$[11$ to 15$]$} & 18 & 0.4 \\
{$[16$ to 20$]$} & 173 & 7.9 \\
{$[21$ to 25$]$} & 33 & 75.9 \\
{$[26$ to 30$]$} & 3 & 14.5 \\
No answer & 19 & 1.3 \\
\hline
\end{tabular}

* Cameroon, Congo, Togo; ** Women in period of widowhood during the study period.

\subsection{Prevalence of HR/HPV Infection}

Among the 247 women of our sample, 81 were HR/HPV positive during PCR. Prevalence of $\mathrm{HR} / \mathrm{HPV}$ infection was $32.8 \%$ [95\% CI: 27.1-39.3]. Age group 20 years or less had the highest prevalence of HR/HPV infection (55.7\%) followed by age group from 21 to 30 years $(38.3 \%)$. Table 2 shows age distribution of $\mathrm{HR} / \mathrm{HPV}$.

Table 2. HR/HPV prevalence by age, Parakou, January to April 2017.

\begin{tabular}{lllll}
\hline & Total & Population size & Percentage & CI 95\% \\
\hline$\leq 20$ years & 9 & 5 & 55.7 & $15.0-96.1$ \\
{$[21-30]$ years } & 107 & 41 & 38.3 & $29.1-45.7$ \\
{$[31-40]$ years } & 75 & 18 & 24.0 & $14.1-33.9$ \\
{$[41-50]$ years } & 44 & 14 & 31.8 & $17.5-46.1$ \\
{$[51-60]$ years } & 12 & 3 & 25.0 & $-3.7-53.7$ \\
Total & 247 & 81 & 32.8 & $27.1-39.3$ \\
\hline
\end{tabular}

All the fourteen HR/HPV genotypes sought for were detected using PCR in our study population. The number of genotypes per woman varied from 1 to 5. Among the population of women who were HR/HPV positive, the most common HR/HPV types were, in descending order (Figure 1): HPV45 (25.9\%), HPV35 (18.5\%), HPV52 (17.3\%), HPV51 $(16.0 \%)$ and HPV58 (14.8\%).

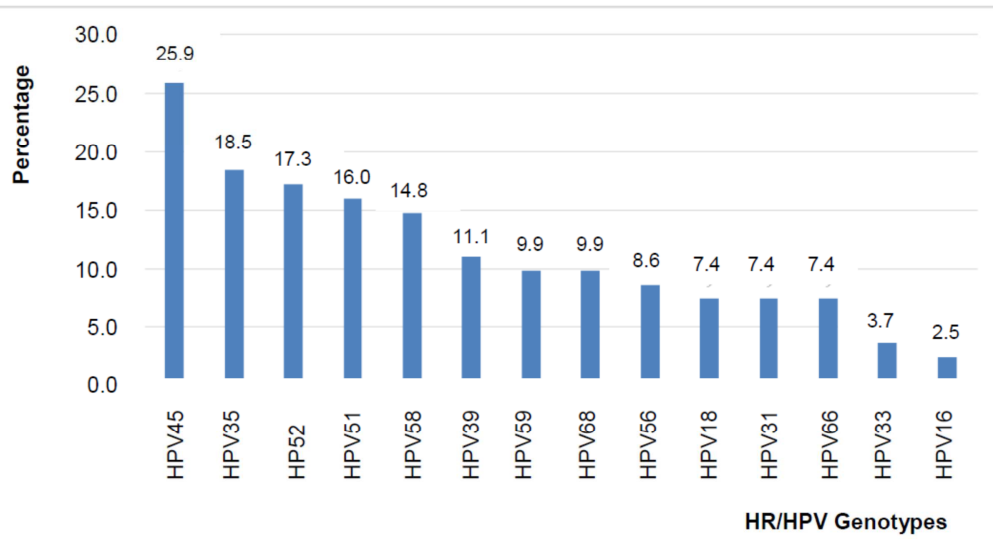

Figure 1. Frequency of HR/HPV genotypes among PCR-positive sexually active women, Parakou, January to April 2017 (n=81). 
Twelve HR/HPV genotypes were associated with isolated infections (50.5\%) and multiple infection was find in $39.5 \%$. Carrying the HR/HPV type was common in the age group from 21 to 30 years in PCR-positive women (Figure 2).

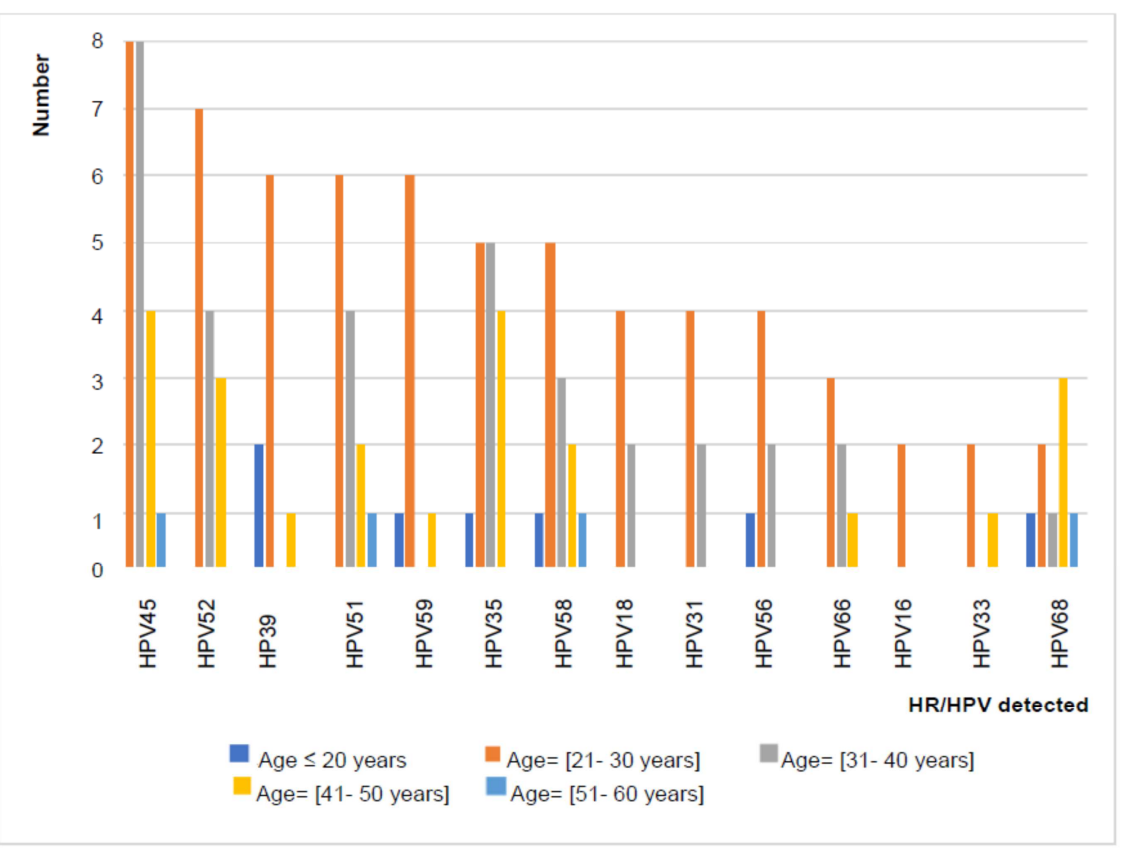

Figure 2. Carrying HR/HPV type according to age group in PCR-positive sexually active women, Parakou, January/April 2017 (n=81).

\section{Discussion}

The prevalence of HR/HPV infection found out in this study i.e. $32.8 \%$ is close to the rates of Ouedraogo et al. [12] in Burkina Faso in 2018 and Winer et al. [18] in the United States in 2012 which were respectively $34.4 \%$ and $35.9 \%$. That prevalence is higher than the ones reported by Traore et al. [11] in Burkina Faso in 2016, Andall-Brereton et al. [19] in the Caribbean in 2017 and Navarro-Vidal et al. [20] in Mexico in 2018 i.e. $25.4 \%, 25.2 \%$ and $14.7 \%$ respectively among populations of sexually active women. Besides, it is above the one found by Schluterman et al. [21] in Mali in $2013(23 \%)$ among a population of rural women. Those data support the view according to which the prevalence of $\mathrm{HR} / \mathrm{HPV}$ infection varies from one region to another [4]. That disparity of prevalences may be due to the variability of exposure to risk factors for HPV infection and to the difference existing between sociocultural contexts from one region to another.

The age specific distribution showed that the highest prevalence of HR/HPV infection was observed in age group 20 years or less followed by age group from 21 to 30 years in our study. The age groups concerned in the study by Ouedraogo et al. [12] in Burkina Faso in 2018 were those aged 25 to 29 and 35 to 39 years with a frequency of $22.1 \%$. In China, the age group of 25 years or less was the most affected by HR/HPV infection (14.8\%) [22]. The HR/HPV infection was common in the age group from 40 to 49 years $(40.6 \%)$ in Mexico [20]. In most of these studies, the prevalence of HR/HPV infection decreases with age. The decrease in the prevalence of HR/HPV in aged women could be related by the sex activity or the immune response status of the women studied [20].

All the fourteen HR/HPV genotypes we sought for $(16,18$, $31,33,35,39,45,51,52,56,58,59,66$ and 68) were detected using PCR among our study population. On the contrary, Traore et al. [11] in Burkina Faso in 2016 did not find out genotypes 16 and 33; equally, Ouedraogo et al. [12] in Burkina Faso in 2018 did not find out genotypes 39 and 59 in their studies by using the same PCR kit (HPV Genotypes 14 Real-TM Quant manufactured by Sacace Biotechnologies, Como, Italy). Therefore, the genotypes circulating from one region to another are not strictly the same. The number of genotypes per woman also varies from one region to another. In this research work, it varied from 1 to 5 . According to the works conducted by Traore et al. [11] in 2016, Ouedraogo et al. [12] in 2018 in Burkina Faso and by Winer et al. [18] in the United States in 2012, that number varied respectively from 1 to 3,1 to 5 and 1 to 7 .

Among the population of HR/HPV positive women included in our study, the most common types of HR/HPV were, in descending order: HPV45 (25.9\%), HPV35 (18.5\%), HPV52 (17.3\%), HPV51 (16.0\%) and HPV58 (14.8\%). In a study conducted by Piras et al. [16] in 2011 within 8 cities of Benin, including Parakou, the most common HR/HPV genotypes were HPV59 (24.7\%), HPV35 (22.5\%), HPV16 (17.6\%), HPV18 (14.8\%) and HPV58 (13.4\%). For Traore et al. [11] in Burkina Faso in 2016, the most common HR/HPV genotypes were HPV39 (18.5\%), HPV52 (16.7\%), HPV18 (14.8\%) and HPV35 (13.0\%). On the contrary, for Manga et al. [15] in Nigeria in 2015, the most common genotypes were HPV16 and 18 in respective proportions of $44.7 \%$ and $13.2 \%$. Data from a cross-sectional descriptive and case-control 
study indicate that the HPV most commonly found out in cervical cancers are HPV16, 18 and 45, in descending order, in North America, South and Central America, in Africa, Asia and Oceania [23]. There is a discrepancy between our findings and those of literature in which HPV 16 is predominant among precancerous and cancerous cervical lesions [24-29]. The present study being limited to systematic screening by PCR without cytological examination of the cervico-vaginal smear and because of the natural viral clearance after two years [4], we cannot therefore establish a formal link between the presence of these HP/VHR and cervical cancer. But our results suggest the genotype of HR/HPV circulating in the study area.

Twelve out of the fourteen HR/HPV genotypes identified in our study were found out by Piras et al. [16] in Parakou in 2011. These are genotypes HPV 59, 35, 16, 18, 58, 45, 56, 33, 51, 31, 52 and 39. Actually, Piras et al. [16] used a kit for the detection of $14 \mathrm{HR} / \mathrm{HPV}$ (ProDect ${ }^{\circledR}$ Chip HPV Typing kit, bes BIOTECH, Cagliari, Italy) which does not include HPV 66 (as in our kit) but rather HPV73. Therefore, the same HR/HPV genotypes have been circulating in Parakou in particular and in Benin in general for some years now. A comparison of our findings to those of Traore et al. [11] shows that HPV35 and HPV52 are frequently found out in Parakou (Benin) and Ouagadougou (Burkina Faso), two cities located in the West African sub-region. In contrast, the most common HR/HPV found out in the study of Ouedraogo et al. [12] in Tenkodogo, another city of Burkina Faso, are HPV56 (36.4\%) and HPV66 (36.4\%). Once again, these results clearly illustrate the variability of HR/HPV infection. Twelve HR/HPV genotypes were associated with isolated infections in this research work. In Benin in 2011, Piras et al. [16] found out nine genotypes (HPV 16, 18, 35, 42, 52, 56, 58, 59 and 73). In the survey conducted by Traore et al. [11] in Burkina Faso in 2016, eleven genotypes (HPV 18, 31, 35, 39, 45, 51, 52, 56, 58, 66 and 68) were associated with isolated infections. Isolated $\mathrm{HR} / \mathrm{HPV}$ genotype infection seems to be predominant as shown in the literature $[12,30,31]$.

The main limitation of the present study is the relatively low number of participants included. In this respect, multicenter studies with higher numbers of participants might be useful to elucidate this area of research.

\section{Conclusion}

It emerges from this research work that the prevalence of $\mathrm{HR} / \mathrm{HPV}$ infection is high among sexually active women in Parakou in 2017. All the fourteen genotypes (HPV-16, 18, 31, $33,35,39,45,51,52,56,58,59,66$ and 68) which were sought for are common in Parakou; HPV45, 35, 52, 51 and 58 are the predominant ones. Monogenomic infection is the most common and the number of genotypes per woman varies from one to five. Genotypes 16 and 18 are found out at a low frequency.

In the light of the above, the two vaccines currently available in our areas (bivalent and quadrivalent) do not provide a good coverage for the women of Parakou. It would therefore be necessary to make available the nonavalent vaccine already used in certain region of the world.

\section{Acknowledgements}

The authors are grateful to the "Agence Universitaire de la Francophonie" (University agency for French speaking countries) which, through its research program on integrated topics, was kind enough to fund this work in the framework of the project "Mapping of High-Risk Human Papillomavirus among sexually active women in the West African region".

\section{Conflict of Interest}

The authors declare that they have no competing interests.

\section{References}

[1] Shi R, Devarakonda S, Liu L, Taylor H, Mills G. Factors associated with genital human papillomavirus infection among adult females in the United States, NHANES 2007-2010. BMC Res Notes. 2014; 7: 544. DOI: 10.1186/1756-0500-7544.

[2] Shaw E, Ramanakumar AV, El-Zein M, Silva FR, Galan L, Baggio ML et al. Reproductive and genital health and risk of cervical human papillomavirus infection: results from the Ludwig-McGill cohort study. BMC Infect. Dis. 2016; 16: 116. DOI: 10.1186/s12879-016-1446-x.

[3] Graham SV. Human papillomavirus: gene expression, regulation and prospects for novel diagnostic methods and antiviral therapies. Future Microbiol. 2010; 5 (10): 1493-1506. DOI: $10.2217 / \mathrm{fmb} .10 .107$

[4] Schiffman M, Doorbar J, Wentzensen N, de Sanjosé S, Fakhry C, Monk BJ et al. Carcinogenic human papillomavirus infection. Nature Reviews Disease Primers. 2016; 2. https://doi.org/10.1038/nrdp.2016.86.

[5] Rodriguez-Cerdeira C, Sanchez-Blanco E, Alba A. Evaluation of Association between Vaginal Infections and High-Risk Human Papillomavirus Types in Female Sex Workers in Spain. ISRN Obstetrics and Gynecology. 2012. Article ID 240190. DOI: $10.5402 / 2012 / 240190$.

[6] Bray F, Ferlay J, Soerjomataram I, Siegel RL, Torre LA, Jemal A. Global Cancer Statistics 2018: GLOBOCAN Estimates of Incidence and Mortality Worldwide for 36 Cancers in 185 Countries. CA: Cancer J Clin. 2018; 68: 394-424. DOI: 10.3322/caac.21492.

[7] Ronco G, Dillner J, Elfström KM, Tunesi S, Snijders PJF, Arbyn $M$ et al. Efficacy of HPV-based screening for prevention of invasive cervical cancer: follow-up of four European randomised controlled trials. Lancet. 2014; 383 (9916): 524-532. DOI: 10.1016/S0140-6736(13)62218-7.

[8] Sankaranarayanan R. HPV vaccination: the most pragmatic cervical cancer primary prevention strategy. Int $\mathrm{J}$ Gynaecol

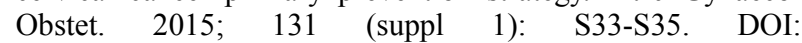
10.1016/j.ijgo.2015.02.014. 
[9] Quan Toh Z, Kosasih J, Russell FM, Garland SM, Mulholland EK, Licciardi PV. Recombinant Human Papillomavirus Nonavalent Vaccine in the Prevention of Cancers Caused by Human Papillomavirus. Infect Drug Resist. 2019; 12: 19511967. DOI: 10.2147/IDR.S178381.

[10] Zohoncon TM, Bisseye C, Djigma FW, Yonli AT, Compaore TR, Sagna T et al. Prevalence of HPV High-Risk Genotypes in Three Cohorts of Women in Ouagadougou (Burkina Faso). Mediterr J Hematol Infect Dis. 2013; 5 (1): e2013059. DOI: 10.4084/MJHID.2013.059.

[11] Traore IMA, Zohoncon TM, Dembele A, Djigma FW, ObiriYeboah D, Traore $\mathrm{G}$ et al. Molecular Characterization of High-Risk Human Papillomavirus in Women in BoboDioulasso, Burkina Faso. Biomed Res Int. 2016. Article ID 7092583. DOI: $10.1155 / 2016 / 7092583$.

[12] Ouedraogo RA, Zohoncon TM, Guigma SP, Traore IMA, Ouattara AK, Ouedraogo $M$ et al. Oncogenic human papillomavirus infection and genotypes characterization among sexually active women in Tenkodogo at Burkina Faso, West Africa. Papillomavirus Research. 2018; 6: 22-26. DOI: 10.1016/j.pvr.2018.09.001.

[13] Jaquet A, Horo A, Charbonneau V, Ekouevi DK, Roncin L, Toure B et al. Cervical human papillomavirus and HIV infection in women of child-bearing age in Abidjan, Côte d'Ivoire. $\mathrm{Br}$ J Cancer. 2010; 107 (3): 556-563. DOI: 10.1038/bjc.2012.299.

[14] Ndiaye C, Alemany L, Ndiaye N, Kamate B, Diop Y, Odida M et al. Human papillomavirus distribution in invasive cervical carcinoma in sub-Saharan Africa: could HIV explain the differences? Trop Med Int Health. 2012; 17 (12): 1432-1440. DOI: $10.1111 /$ tmi. 12004 .

[15] Manga MM, Fowotade A, Abdullahi YM, El-nafaty AU, Adamu DB, Pindiga HU et al. Epidemiological patterns of cervical human papillomavirus infection among women presenting for cervical cancer screening in North-Eastern Nigeria. Infectious Agents and Cancer. 2015; 10: 39. DOI 10.1186/s13027-015-0035-8.

[16] Piras F, Piga M, De Montis A, Zannou ARF, Minerba L, Perra MT et al. Prevalence of human papillomavirus infection in women in Benin, West Africa. Virol J. 2011; 8: 514. DOI: 10.1186/1743-422X-8-514.

[17] Zohoncon TM, Ouédraogo TC, Brun LVC, Obiri-Yeboah D, Djigma WF, Salifou K et al. Molecular Epidemiology of High-Risk Human Papillomavirus in High-Grade Cervical Intraepithelial Neoplasia and in Cervical Cancer in Parakou, Republic of Benin. Pak. J. Biol. Sci. 2016; 19: 49-56. DOI: $10.3923 /$ pjbs.2016.

[18] Winer RL, Hughes JP, Feng Q, Fu Xi L, Lee SK, O'Reilly SF et al. Prevalence and risk factors for oncogenic HPV infections in high-risk mid-adult women. Sex Transm Dis. 2012; $\quad 39 \quad$ (11): $\quad 848-856 . \quad$ DOI: 10.1097/OLQ.0b013e3182641f1c.

[19] Andall-Brereton G, Brown E, Slater S, Holder Y, Luciani S, Lewis $\mathrm{M}$ et al. Prevalence of high-risk human papillomavirus among women in two English-speaking Caribbean countries. Rev Panam Salud Publica. 2017; e41: e41.

[20] Navarro-Vidal E, Hernandez-Rosas F, Rey M, Flores-Peredo L.
Prevalence of Human Papillomavirus Genotypes in Women from Cozumel, Mexico. Asian Pac J Cancer Prev. 2018; 19 (9): 2417-2422. DOI: 10.22034/APJCP.2018.19.9.2417.

[21] Schluterman NH, Sow SO, Traore CB, Bakarou K, Dembelé R, Sacko $\mathrm{F}$ et al. Differences in patterns of high-risk Human papillomavirus infection between urban and rural lowresource settings: cross-sectional findings from Mali. BMC Womens Health. 2013; 13: 4. DOI: 10.1186/1472-6874-13-4.

[22] Wang J, Tang D, Wang K, Wang J, Zhang Z, Chen Y et al. HPV genotype prevalence and distribution during 2009-2018 in Xinjiang, China: baseline surveys prior to mass HPV vaccination. BMC Women's Health. 2019; 19: 90. DOI: 10.1186/s12905-019-0785-3.

[23] de Sanjose S, Quint WGV, Alemany L, Geraets DT, Klaustermeier JE, Lloveras B et al. Human papillomavirus genotype attribution in invasive cervical cancer: a retrospective cross-sectional worldwide study. Lancet Oncol. 2010; 11: 1048-1056. DOI: 10.1016/S1470-2045(10)70230-8.

[24] Clifford GM, Goncalves MA, Franceschi S. Human papillomavirus types among women infected with HIV: a meta-analysis. AIDS 2006; 20 (18): 2337-2344. DOI: 10.1097/01.aids.0000253361.63578.14.

[25] Panatto D, Amicizia D, Tanzi E, Bianchi S, Frati ER, Zotti $\mathrm{CM}$ et al. Prevalence of human papillomavirus in young Italian women with normal cytology: how should we adapt the national vaccination policy? BMC Infect. Dis. 2013; 13: 575. DOI: $10.1186 / 1471-2334-13-575$.

[26] Guettiti H, Ennaifer E, Attia L, Chelly D, Alaya NB, Aissa RB et al. Pre-vaccination prevalence and genotype distribution of human papillomavirus infection among women from urban Tunis: a cross-sectional study. Asian Pac. J. Cancer Prev. 2014 15 (21): 9361-9365. DOI: 10.7314/apjcp.2014.15.21.9361.

[27] Monsonego J, Cox JT, Behrens C, Sandri M, Franco EL, Yap PS et al. Prevalence of high-risk human papilloma virus genotypes and associated risk of cervical precancerous lesions in a large U.S. screening population: data from the ATHENA trial. Gynecol. Oncol. 2015; 137 (1): 47-54. DOI: 10.1016/j.ygyno.2015.01.551.

[28] Zhao XL, Hu SY, Zhang Q, Dong L, Feng RM, Han R et al. High-risk human papillomavirus genotype distribution and attribution to cervical cancer and precancerous lesions in a rural Chinese population. J Gynecol Oncol. 2017; 28 (4): e30. DOI: 10.3802/jgo.2017.28.e30.

[29] Zhu C, Wang Y, Mao W, Zhang H, Ma J. Prevalence and distribution of HPV types in genital warts in Xi'an, China: a prospective study. BMJ Open. 2019; 9: e023897. DOI: 10.1136/bmjopen-2018-023897.

[30] Kavanagh K, Sinka K, Cuschieri K, Love J, Potts A, Pollock $\mathrm{KG}$ et al. Estimation of HPV prevalence in young women in Scotland; monitoring of future vaccine impact. BMC Infect. Dis. 2013; 13: 519. DOI: 10.1186/1471-2334-13-519.

[31] Dareng EO, Adebamowo SN, Famooto A, Olawande O, Odutola MK, Olaniyan Y et al. Prevalence and incidence of genital warts and cervical Human Papillomavirus infections in Nigerian women. BMC Infect. Dis. 2019; 19: 27. DOI: 10.1186/s12879-018-3582-y. 